\title{
The Intermediary Reactions of Fermentation*
}

\section{By Prof. Otto Meyerhof, For. Mem. R. S., Physiology Department, Kaiser Wilhelm Institute for Medical Research, Heidelberg}

$\mathrm{I}_{\mathrm{s}}^{\mathrm{N}}$ $\mathrm{N}$ what way and by what mechanism is the sugar molecule transformed in the cell under anærobic conditions into its biological end-products, alcohol and carbon dioxide in the case of yeast, or lactic acid in the case of muscle? The different kinds of anærobic breakdown of carbohydrate are so closely related, the anærobic formation of lactic acid especially offers so many analogies to alcoholic fermentation, that the discussion of one will throw much light on the other.

Just as a cell-free yeast extract could be made according to the prescriptions of Buchner and Lebedew, so a glycolysing extract of muscle could be obtained and both systems could be divided further. The co-enzyme systems could be removed by dialysis and the protein residues could be fractionated in various ways. In addition to such fractionation, it is possible to suppress certain enzyme reactions by specific poisons, leaving others undamaged, and by other means to remove from further reaction certain intermediate products. At the end, one arrives at certain elementary or primary reactions by which, step by step, substances structurally adjacent are converted one into the other.

In these intermediary reactions, four different types are obvious. The most familiar type is oxidation-reduction. This oxidation-reduction is confined to three distinct reactions, which are connected by the cozymase of Harden and Euler. The chemical constitution and the function of this cozymase have been revealed by Otto Warburg during the past year. The cozymase was identified as diphosphopyridine-nucleotide, where the $\mathrm{H}_{2}$ carrying group is nicotinic acid amide (scheme 1 ).

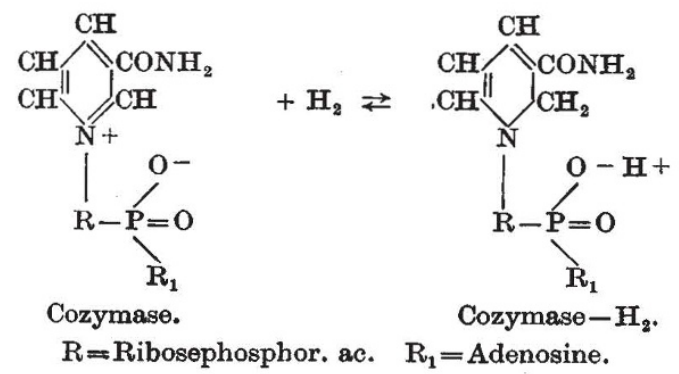

(1)

The reduction process consists of the conversion of acetaldehyde, which arises in fermentation, to alcohol. The oxidation has been achieved by o. Warburg with hexosemonophosphate; but in fermentation this monophosphate is not the molecule which reacts directly with cozymase but a more remote primary product. The oxidation process, which reduces the cozymase, consists of the conversion of triosephosphate (more exactly glyceraldehydephosphate) into phosphoglyceric acid. The oxidation-reduction consists of the reduction of aldehyde to alcohol, and the oxidation of phosphorylated aldehyde to phosphorylated carboxy acid. This is the oxidationreduction in the stationary state of fermentation where acetaldehyde is already present as split product of pyruvic acid. In the beginning, during the so-called induction period, the phosphoglyceric acid arises by the dismutation of triosephosphoric acid alone, while simultaneously $\alpha$-glycerophosphoric acid is formed as reduction product. This dismutation also is brought about by cozymase.

The yeast dialysate, designated originally as coenzyme of fermentation by Harden, does not contain only the cozymase, but several other constituents as well. One of these is a second coenzyme which also can be regarded as the dissociable active group of an enzyme, namely the phosphorylating coenzyme. This coenzyme is the so-called adenylic system. It consists of three parts: (a) adenylic acid (adenosinmonophosphate), (b) adenosindiphosphate, and $(c)$ adenosintriphosphate. The last two substances were discovered by K. Lohmann in our Institute. The transfer of phosphate is brought about by adenylic acid or adenosindiphosphate taking up phosphate, and adenosintriphosphate giving it off. The substance which accepts phosphate from adenosintriphosphate is hexose. It first becomes hexosemonophosphate and then hexosediphosphate, the wellknown ester of Harden and Young. On the other hand, only one substance gives off phosphate. This is the precursor of pyruvic acid, phosphopyruvic acid. In splitting phosphopyruvic acid, the phosphate group is transferred to a sugar or hexose. monophosphate molecule, according to the following scheme (2).

$$
\begin{aligned}
& \text { A. } 2 \text { phosphopyruvic acid +adenylic acid }= \\
& 2 \text { pyruvic acid +adenosintriphosphoric acid } \\
& \text { B. } 2 \text { glucose + adenosintriphosphoric acid = } \\
& 2 \text { hexosemonophosphoric acid + adenylic acid } \\
& C=\underline{A+B} \text { phosphopyruvic acid }+ \text { glucose }= \\
& \text { pyruvic acid thexosemonophosphoric acid } \\
& D \text {. phosphopyruvic acid thexosemonophosphoric acid }=
\end{aligned}
$$


This chain of reactions goes very much faster than the direct splitting into pyruvic acid and inorganic phosphate, and is a typical example of transfer of phosphate.

The oxidation-reduction and the phosphorylations are the most important links of the reaction chain from the energetic point of view, but with these two types of reactions the series is not yet. complete. If one removes all coenzymes by dialysis, such an extract is inactive towards hexose, also towards hexosemonophosphate, but not towards hexosediphosphate. In 1934, I found, together with K. Lohmann, that hexosediphosphate enters a very fast reversible reaction, namely hexosediphosphate $\rightleftharpoons$ 2-dihydroxyacetonephosphate. Here the 6-C chain is split reversibly into 3-C chains. The closer investigation of this remarkable reaction revealed the fact that it must be separated into the two reactions given in scheme 3 .

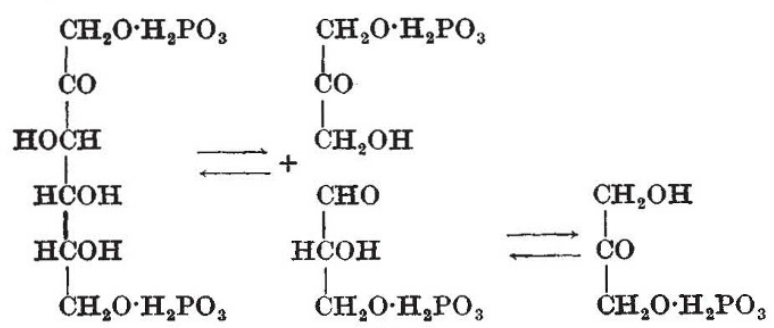

In the first reaction, one half of the molecule is converted into 3-glyceraldehyde-phosphate, synthesized by H. Fischer two years earlier. This 3 -glyceraldehyde-phosphate is then largely converted into dihydroxyacetone-phosphate. In the opposite direction the two trioses react by enzymatic aldol condensation to form hexosediphosphate. The other reversible reactions described below are also independent of a coenzyme. In 1933 Embden discovered shortly before his death that phosphoglyceric acid is converted enzymatically into pyruvic acid and phosphate. The closer investigation of this Embden reaction taught us that here also a reaction chain occurs which must be formulated as in scheme 4.

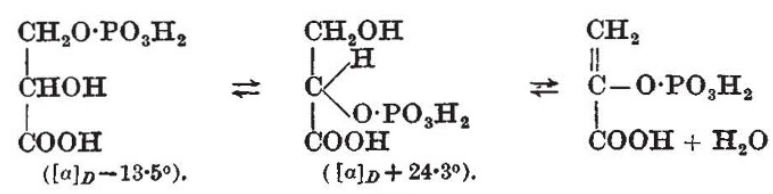

(4)

Between 3-phosphoglyceric acid, 2-phosphoglyceric acid and phosphopyruvic acid a reversible equilibrium exists. The conversion of the last into pyruvic acid is an irreversible dephosphorylation, as I have already stated.

In pursuing the further fate of the pyruvic acid we meet the fourth type of fermentation reaction, the breakdown of pyruvic acid into acetaldehyde and carbon dioxide by the well-known carboxylase of Neuberg. This carboxylase also has a dissociable group which was identified by $\mathbf{K}$. Lohmann a short time ago as the pyrophosphate of aneurin (vitamin $B_{1}$ ).

I have put down all these intermediary products in scheme 5, where the chemically adjacent substances follow each other directly. Every substance is distinguished from the preceding one either by one phosphate group, one carboxyl group, one water group, an oxidative stage, or the neighbouring position of phosphate. Any other stable intermediates are, therefore, highly improbable.

$$
\begin{aligned}
& \text { glucose (glycogen, fructose, etc.) } \\
& \downarrow+1 \mathrm{H}_{3} \mathrm{PO} \text {. } \\
& \text { glucose-6-phosphor. ac. ‡ fructose-6-phosphor. ac. } \\
& \downarrow+1 \mathrm{H}_{3} \mathrm{PO}_{4} \\
& \text { fructose }(-1-6 \rightarrow) \text { phosphor. ac. }
\end{aligned}
$$

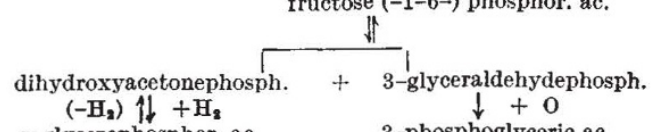

$$
\begin{aligned}
& \text { a-glycerophosphor. ac. } \\
& \text { (glycerol }+1 \mathrm{H}_{3} \mathrm{PO}_{4} \text { ) } \\
& \text { lactic acid } \\
& \leftarrow+\underline{H}_{8} \\
& \begin{array}{l}
\text { 3-phosphoglyceric ac. } \\
\text { 2-phosphoglyceric ac. } \\
\text { phosphopyruvic ac. } \\
\downarrow \\
\text { pyruvic acid }+1 \mathrm{H}_{3} \mathrm{PO}_{4} \\
\downarrow \\
\text { acetaldehyde }+\mathrm{CO}_{3} \\
\downarrow+\mathrm{H}_{2} \\
\text { ethyl alcohol }
\end{array}
\end{aligned}
$$$$
\text { (5) }
$$

Does this scheme also indicate the pathway by which in the stationary state the breakdown really proceeds? I can answer the question in the affirmative. Some investigators claimed the hexosemonophosphate to be the reactive form of sugar, because it ferments more rapidly than does the Harden-Young ester. Some time ago I myself was also in favour of this opinion. On the other hand, the ester of Harden-Young was not popular in this respect, for the reason that it ferments very slowly and does not decrease during the rapid period of fermentation, but even accumulates, which seems strange for an intermediary product. Only in the past year have we succeeded in solving this paradox by the closer study of the so-called 'fermentation test' of Warburg and Christian.

These investigators have obtained from maceration juice of yeast two different fractions of protein, partially purified, so-called $A$ - and $B$-proteins, which, together with the total system of coenzymes, are able to decompose hexosemonophosphate in the presence of acetaldehyde into phosphoglyceric acid and pyruvic acid. (The carboxylase is removed by this fractionation.) Glucose alone and also hexosediphosphate alone remain practically unattacked in this fermentation test. It appeared as though hexosemonophosphate by the 
interaction of acetaldehyde would split into two oxidized halves, namely, pyruvic acid and phosphoglyceric acid. This finding contradicted all our experience, according to which the whole of pyruvic acid is derived from phosphopyruvic acid. The study of this fermentation test had an unexpected result : it could be proved with convincing evidence that the structural chemical sequence of substances is identical with the pathway of breakdown. Why, I should like to ask, can hexosemonophosphate be metabolized only with both protein fractions $A$ and $B$ together? This follows, as our experiments show, from the fact that the so-called $A$ protein contains that enzyme which in co-operation with the adenylic system enables the phosphate transfer in equation $F$ of scheme 6 .

\section{$E .1$ hexosediphosphoric acid it. \\ 2 triosephosphoric acid +2 acetaldehyde +2 glucose $+2 \mathrm{H}_{3} \mathrm{PO}$, $=2$ phosphoglyceric acid +2 alcohol +2 hexosemonophosphoric \\ F. 2 hexosemonophosphoric acid +2 phosphoglyceric acid $=2$ hexosediphosphoric acid +2 pyruvic acid \\ $G=E+F$ \\ 1 hexosediphosphoric acid +2 acetaldehyde + \\ $=2$ pyruvic acid +2 alcohol +2 hexosediphos- phoric acid $H=G+$ carboxylase : 1 hexosediphosphoric acid +2 glucose + \\ $=2 \mathrm{CO}_{2}+2$ alcohol +2 hexosediphosphoric acid}

(6)

If no hexosediphosphate can originate, no fermentation takes place because hexosediphosphate is the only source of triosephosphate. Accordingly, a fermentation comes about with $B$-protein alone, if one starts with a mixture of glucose and hexosediphosphate, since now the hexosediphosphate can be decomposed into triosephosphate ( $E$ of scheme 6). Two molecules of triosephosphate, which originate from the rapid breakdown of one molecule of hexosediphosphate, are oxidized by acetaldehyde to phosphoglyceric acid; the acetaldehyde is reduced to alcohol, while simultaneously two molecules of glucose are esterified to hexosemonophosphate. On subsequent addition of the phosphorylating enzyme, that is, the $A$ protein, the above-mentioned reaction $F$ will be obtained. Hexosemonophosphate takes up phosphate from phosphopyruvic acid which originates from phosphoglyceric acid. When we sum up equations $E$ and $F$ and consider that two molecules of triose. phosphate are equal to one molecule of hexosediphosphate, we obtain the balance equation $G$ of scheme 6. In this balance, hexosemonophosphate and phosphoglyceric acid are cancelled as intermediates, since they appear on both sides. Now, for the turnover of two molecules of glucose we get one molecule of hexosediphosphate in addition; but while equation $E$ indicates a stoichiometrical reaction, this is no longer the case with equation $G$.
Hexosediphosphate increases autocatalytically and always reacts anew by way of triosephosphate according to equation $E$, until another component, for example glucose or inorganic phosphate, is completely consumed.

Equation $G$ is nothing but the fundamental reaction on which the Harden-Young equation is based. In our case the carboxylase was removed by fractionating the proteins. When we add this carboxylase, by which the pyruvic acid is split into acetaldehyde and carbon dioxide, we arrive at the total balance $H$ of scheme 6 . Now the acetaldehyde also is cancelled in the balance and we obtain the Harden-Young equation itself by merely removing one molecule of hexosediphosphate from each side. It is, however, advisable to leave this hexosediphosphate as it is in equation $H$, because this emphasizes that really hexosediphosphate is converted into alcohol and carbon dioxide, while glucose represents the acceptor of phosphate. In the balance, according to the Harden-Young reaction, free sugar disappears and hexosediphosphate accumulates. However, according to the mechanism it is in fact entirely different, for the hexosediphosphate is the mother substance of the triosephosphate which reacts directly with cozymase, while glucose is being converted into diphosphate by way of hexosemonophosphate, according to equations $E$ and $F$. I remind you of a finding obtained twenty years ago, that maceration juice free from autofermentation does not decompose sugar, without a trace of hexosediphosphate having been added in the beginning. This is the hexosediphosphate on the left side of equation $H$.

In respect to the fermentation of hexosemonophosphate studied by Warburg, it can also be shown that the mechanism is the same. The hexosemonophosphate is at first converted into hexosediphosphate by taking up phosphate, and equations quite analogous to those demonstrated are valid. As a matter of fact, the pyruvic acid which appears in this fermentation of hexosemonophosphate has derived from phosphopyruvic acid by the transfer mechanism of phosphate, as shown in equation $F$ of scheme 6 .

It is always the triosephosphoric acid which reacts directly with cozymase. But this reaction proceeds slowly by itself, and is rapid only in the presence of a substrate functioning as acceptor of phosphate. A most convincing demonstration can be given by substituting creatine for glucose in the fermentation system of hexosediphosphate. Creatine, as is well known, is not present in yeast, but it is of fundamental importance in the lactic acid formation of muscle as acceptor of phosphate. If one adds to the $B$ protein of Warburg, in addition to the different coenzymes, 
hexosediphosphate and creatine and a little of the specific enzyme which enables the phosphate transfer from adenylpyrophosphate to creatine, hexosediphosphate will now be decomposed into pyruvic acid as rapidly as in the presence of glucose.

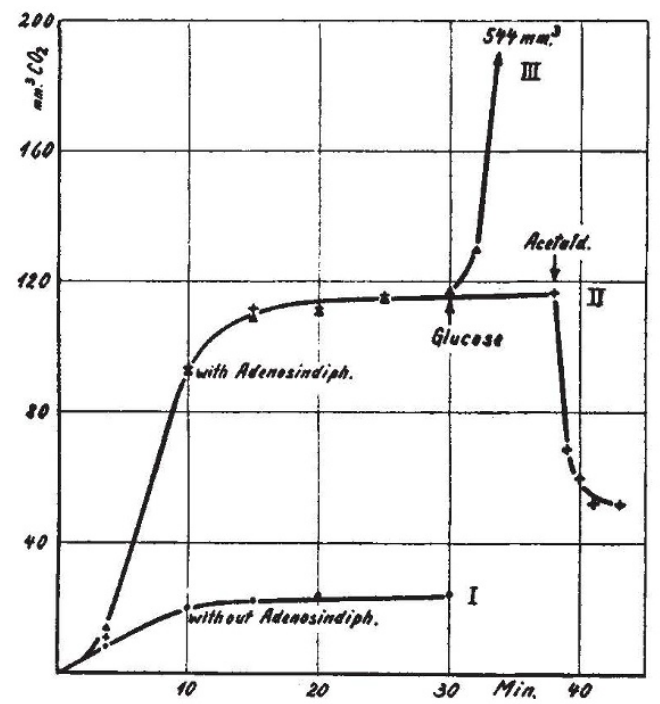

MANOMETRIC DETERMMNATION OF REDUCTION OF COZYMASF BY TRIOSEPHOSPHORIC ACID IN PRESENCE OF B-PROTFIN. CARBON DIOXIDE IIBERATION IROM SODIUM BICARBONATE BY H + OF REDUCED COZYMASE AND $\mathrm{H}+$ OF PHOSPHOGLYCERIC ACID.

The specific relation between the oxidationreduction and the uptake of inorganic phosphate, which has also impressed other investigators, can be traced to a coupling of the reduction of cozymase and the phosphorylation of adenylic acid or adenosindiphosphate to adenosintriphosphate. When we omit acetaldehyde from our system and employ triosephosphate and cozymase in equiva. lent amounts, only a very slow reaction takes place; but this reaction is accelerated enormously as soon as either a larger quantity of adenosindiphosphate or an excess of glucose with a trace of an adenylic compound is added. In the accompanying diagram the course of this conversion is demonstrated.

The measurements were made with manometric technique. The second curve is with a large amount of adenosindiphosphate. The steep upward branch of the curve shows the effect of adding glucose as indicated. This interacts with the adenosintriphosphate formed by phosphate transfer to adenosindiphosphate. The curve sloping downward shows the effect of adding acetaldehyde, by which the reduced cozymase is reoxidized. In addition to this manometric method, the hydrogenation of cozymase can be measured spectrographically. As discovered by 0 . Warburg, the reduced cozymase has a broad absorption band at $340 \mathrm{~m} \mu$, which is lacking in the oxidized form. From the breadth of the band the amount of reduced cozymase can be calculated. Thus, by different methods one arrives at the equations in scheme 7.

$$
\begin{gathered}
J . \begin{array}{l}
1 \text { triosephosphate }+1 \mathrm{Cz}+1 \text { adenosindiphosphate }+\mathrm{H}_{2} \mathrm{PO}_{4} \\
=1 \text { phosphoglyceric acid }+1 \mathrm{Cz}_{\mathbf{4}}+1 \text { adenosintriphosphate } \\
\text { K. } 1 \text { adenosintriphosphate }+1 \text { glucose } \\
=1 \text { adenosindiphosphate }+1 \text { hexosemonophosphate }
\end{array} \\
\hline L=J+K, \begin{array}{c}
1 \text { triosephosphate }+1 \mathrm{Cz}+1 \text { Glucose }+1 \mathrm{H}_{8} \mathrm{PO} \\
=1 \text { phosphoglyceric acid }+1 \mathrm{CzH}_{\mathbf{2}}+1 \text { hexosemono- } \\
\text { phosphate }
\end{array}
\end{gathered}
$$

(7)

Always we obtain an equivalence between esterified phosphate, reduction of cozymase, and form. ation of phosphoglyceric acid. The profound cause for this coupling between the adenylic system and the reduction of cozymase (equation $G$ ) remains to be explained.

\section{Basin Cultivation in the United States \\ By Lois Olson, Soil Conservation Service, United States Department of Agriculture}

\begin{abstract}
IN an article entitled "Soil Conservation in 1 Tropical Africa" (NATURE, 141, 268-270; Feb. 12, 1938), Dr. L. Dudley Stamp described a basin type of cultivation that is in practice in Northern Nigeria. In conclusion he states, "If America could invent a plough which will imitate the Nigerian system by replacing the long furrow by a series of isolated elongated basins, one at least of her major problems in the dry lands of the Middle West might be solved". Actually, the principle of basin cultivation described by Dr.
\end{abstract}

Dudley Stamp has been the subject of experimentation in the United States for the last ten years, and to-day several basin cultivators are on the market and in use by farmers in various parts of the country.

So early as 1927, Mr. C. T. Peacock, a Colorado ranch owner, developed a basin lister* which proved satisfactory on his land. The damming attachment consisted of a drag which followed the cutting blade. At intervals the drag was lifted,

* A double mould board plough. 